\title{
Pemuda Dalam Kontestasi Politik : Melacak Alasan Rasional Calon Anggota Legislatif Muda DPRD Kota Pekanbaru Di Pemilihan Legislatif Tahun 2019
}

\author{
${ }^{1}$ Agung Wicaksono, ${ }^{2}$ Budi Mulianto, ${ }^{3}$ Rijalul Fikri, ${ }^{4}$ Hendi Selwa \\ ${ }^{1234}$ Universitas Islam Riau, \\ e-mail :agung.wicaksono@soc.uir.ac.id
}

\begin{abstract}
Abstrak
Salah satu fenomena menraik dalam Pemilihan Umum (Pemilu) 2019 yakni mulai aktifnya para pemuda untuk terlibat langsung dalam dunia politik praktis. Pada tataran yang lebih khusus, keaktifan para pemuda dalam berpolitik di tandai dengan mulai banyaknya calon anggota legislatif (Caleg) muda yang bertarung untuk menduduki posisi sebagai wakil rakyat di berbagai tingkatan pemilihan. Ada yang mencalonkan diri untuk DPRD Kabupaten/Kota, DPRD Provinsi, bahkan hingga DPR-RI maupun DPD-RI. Penelitian ini berkaitan dengan kajian politik praktis di ranah Pemilihan Umum. Peneliti tertarik dengan isu-isu elektoral yang berkenaan dengan contestasi politik para calon anggota legislatif (Caleg) Muda yang maju dalam Pemilihan Legislatif 2019. Terjadi peningkatan antusiasme para pemuda dalam ikut berpolitik secara aktif. Penelitian ini berkaitan dengan untuk mencari alasan rasional yang melatar belakangi caleg muda untuk mencalonkan diri di Pemilihan legislatif 2019. Dalam kaitannya dengan penelitian ini, peneliti focus untuk meneliti caleg muda yang berkompetisi di DPRD Kota Pekanbaru Provinsi Riau.Kajian ini tentunya diharapkan menjadi kajian yang bermanfaat bagi mahasiswa karena peneliti telah melakukan kajian secara langsung mengenai alasan rasional caleg muda untuk berkontestasi dalam politik khususnya di DPRD Kota Pekanbaru. Adapun yang menjadi penerbit tujuan peneliti adalah Marpoyan Tujuh Publishing. Tingkat Kesiapterapan Teknologi yang diusulkan adalah TKT pada level 2. Peneliti menggunakan teori pilihan rasional sebagai teori utama yang kemudian diaplikasikan dengan fenomena kemunculan banyakny acaleg muda yang berkompetisi di DPRD Kota Pekanbaru pada Pemilihan Legislatif 2019.
\end{abstract}

Kata kunci :Pemilihan Legislatif 2019; Pilihan Rasional; Caleg Muda

\begin{abstract}
One of the interesting phenomena in the 2019 General Election (Pemilu) is the active start of youth to be directly involved in the world of practical politics. At a more specific level, the activeness of young people in politics is marked by the number of young legislative candidates (Caleg) who are fighting for positions as people's representatives at various levels of elections. There are those who run for Regency / City DPRD, Provincial DPRD, even DPR-RI and DPD-RI. This research is related to the study of practical politics in the realm of general elections. Researchers are interested in electoral issues relating to the political contestation of young legislative candidates who are advancing in the 2019 Legislative Election. There has been an increase in the enthusiasm of youth in actively participating in politics. This research is related to finding rational reasons behind young candidates to run for the 2019 legislative election. In relation to this research, researchers focused on examining young candidates competing in the DPRD Pekanbaru City, Riau Province.This study is certainly expected to be a useful study for students because researchers have conducted a direct study of the rational reasons for young candidates to compete in politics, especially in the Pekanbaru City DPRD. As for the publisher of the researcher's goal is MarpoyanTujuh Publishing. The level of technological readiness proposed is TKT at level 2. The researcher uses rational choice theory as the main theory which is then applied to the phenomenon of the emergence of many young candidates competing in the Pekanbaru City DPRD in the 2019 Legislative Election.
\end{abstract}

Keywords: 2019 Legislative Election; Rational Choice; Young Candidates 


\section{PENDAHULUAN}

Tahun 2019 bisa disebut sebagai tahun politik yang sebenarnya. Di tahun 2019, sebuah perhelatan akbar demokrasi digelar. Pemilihan Umum (Pemilu) akan dilakukan pada tanggal 17 April 2019. Pemilu sekarang berbeda dengan Pemilu yang ada pada tahun tahun sebelumnya. Pemilu 2019 menyatukan pemilihan Presiden dan Pemilihan Legislatif dalam satu kali saja. Otomatis, dalam waktu 1 hari, seluruh warga negara Indonesia yang sudah memiliki hak untuk memili hak anmen dapatkan 5 kertas suara. Kertas suara tersebut adalah Kertas untuk DPRD Kabupaten/Kota, DPRD Provinsi, DPR-RI, DPD-RI serta kertas suara untuk memilih Presiden dan Wakil Presiden. Terlepas dari persoalan teknis mengenai Pemilu, ada satu hal yang patut di cermati yaitu mulai aktifnya para pemuda untuk aktif dalam berpolitik. Ada pergeseran nilai bahwa politik bukan hanya urusan orang tua, melainkan juga urusan para pemuda yang notabene adalah calon penerus generasi bangsa.

Pergeseran nilai itu dengan mudah ditandai dengan aktifitas politik di media sosial. Para pemuda turut aktif bersuara tentang politik dari mulai hanya sebatas berkomentar hingga turut berkampanye secara aktif mengenai pilihan politiknya di berbagai platform media social seperti Instagram, Facebook, Youtube hingga Twitter. Dalam tataran yang lebih praktis, keaktifan para pemuda dalam berpolitik di tandai dengan mulai banyaknya calon anggota legislatif (Caleg) muda yang bertarung untuk menduduki posisi sebagai wakil rakyat di berbagai tingkatan pemilihan. Ada yang mencalonkan diri untuk DPRD Kabupaten/Kota, DPRD Provinsi, bahkan hingga DPR-RI maupun DPD-RI. Untuk Skala Provinsi Riau, data menunjukkan bahwa Caleg Muda yang paling banyak berkompetisi adalah di DPRD Kota Pekanbaru Peneliti tertarik untuk mengetahui alasan rasional yang melatar belakangi para caleg muda DPRD Kota Pekanbaru untuk mencalonkan diri di Pemilihan Legislatif 2019. Alasan rasional ini dapat dilacak agar khalayak umum dapat mengetahui niat sesungguhnya dari pada caleg muda yang bertarung tersebut.

Pemuda dalam konteks penelitian ini dibatasi yakni dibawah umur 30 Tahun (Sesuai UU Nomor 40 Tahun 2009 tentang Kepemudaan). Dimasa-masa tersebut, banyak pemuda yang masih mencari jati diri, terutama perihal lapangan pekerjaan. Ada indikasi pergeseran makna bahwa menjadi anggota DPRD adalah salah bentuk jalan pintas mencari kerja bagi para pemuda. Biar pun tidak dinafikkan, banyak juga caleg muda yang betul-betul ingin menjadikan status sebagai anggota dewan sebagai jalan untuk mengabdi kepada rakyat.

Penelitian ini adalah penelitian yang berkaitan dengan Perilaku Politik (political behaviour). Secara praktis, tujuan khusus penelitian ini adalah ingin melihat bagaimana alasan rasional para caleg muda untuk jadi wakil rakyat yang dalam penelitian ini di DPRD Kota Pekanbaru. Ini penting untuk diketahui agar bisa menjadi bahan masukan bagi para policy makers dalam membuat kebijakan-kebijakan yang berkaitan dengan Pemilihan Umum. Teori pilihan rasional digunakan sedikit berbeda yakni dari perspektif actor politik (politikus), bukan dari perspektif pemilih (voters) sebagai mana teori ini sering digunakan. Skema yang peneliti ikuti pada penelitian ini adalah skema Penelitian Dasar Dosen Pemula karena memang posisi keilmuan peneliti saat ini masih berada pada tahapan dasar yang ingin melihat realitas atau fenomena social sesuai dengan bidang keilmuan penulis yakni Ilmu Pemerintahan.

\section{METODE}

Penelitian ini menggunakan metode penelitian kualitatif dengan pendekatan studi kasus yang dapat menjelaskan suatu kasus atau peristiwa secara detail (Yin, 2006). Sebelum menentukan judul atau tema penelitian ini, peneliti sudah melakukan observasi awal dengan melihat fenomena banyak munculnya para caleg muda tampil mengenalkan diri kepada publik. Hal ini memicu ketertarikan peneliti 
untuk meneliti mengenai fenomena tersebut. Kemudian peneliti tertarik untuk meneliti alasan rasional para caleg muda tersebut untuk mengikuti Pemilihan Legislatif 2019.

Peneliti kemudian menentukan lokus penelitian pada tingkatan DPRD Kota Pekanbaru karena berdasarkan informasi yang peneliti dapat dari KPU, caleg muda untuk DPRD Kota Pekanbaru adalah yang terbanyak di Provinsi Riau. Dari data dan informasi yang telah penulis peroleh tersebut maka terbentuklah proposal ini sebagai pengantar awal yang dapat menjelaskan permasalahan yang akan diteliti. Adapun penulis dibantu oleh anggota pengusul yang bertugas untuk melakukan pengumpulan data, sedangkan yang melakukan obeservsi prariset adalah peneliti sendiri. Langkah selanjutnya adalah peneliti mulai melakukan identifikasi untuk menentukan informan-informan yang akan dijadikan sebagai sumber data primer.

Peneliti menggunakan Purposive Sampling karena peneliti menentukan informan yang di wawancarai telah ditentukan berdasarkan pemahaman informan dan kebutuhan data (Tongco, 2007). Setelah penentuan informan selesai makan kemudian peneliti menyiapkan daftar-daftar pertanyaan yang akan ditanyakankepada informan yang tentunya telah peneliti sesuaikan dengan teori dan pertanyaan penelitian yang telahpeneliti tetapkan sebelumnya. Kemudian, peneliti akan melakukan wawancara terhadap informan satu per satu hingga semua informan yang telah ditentukan berhasil di wawancarai. Setelah itu kemudian penelitibersama anggota pengusul melakukan analisis data hasil wawancara. Setelah data wawancara dianalisis, maka kemudian peneliti kembali mengecek apakah data promer tersebut sudah cukup kuat untuk kemudianditarik kesimpulan penelitian.

Apabila belum cukup, maka peneliti kembali melengkapi data dengan melakukan wawancara kembali kepada pihak-pihak yang dapat melengkapi kekurangan data tersebut. Setelah itu peneliti bersama anggota pengusul juga melacak sumber-sumber sekunder yang berkaitan dengan penelitian ini untuk semakinmemperkuat data. Data-data dokumentasi lapangan selama penelitian juga peneliti kumpulkan untuk semakin memperkuat keabsahan data. Data-data dokumentasi lapangan dikumpulkan oleh anggota pengusul. Setelah seluruh rangkaian penelitian ini selesai, peneliti yang dibantu dengan anggota pengusul mempersiapkan luaran wajib penelitian berupa artikel pada Jurnal Nasional Terakreditasi dan luaran tambahan chapter book ber-ISBN. Untuk dapat memahami secara mudah proses penelitian ini, maka berikut peneliti sajikan diagram alir proses penelitian:
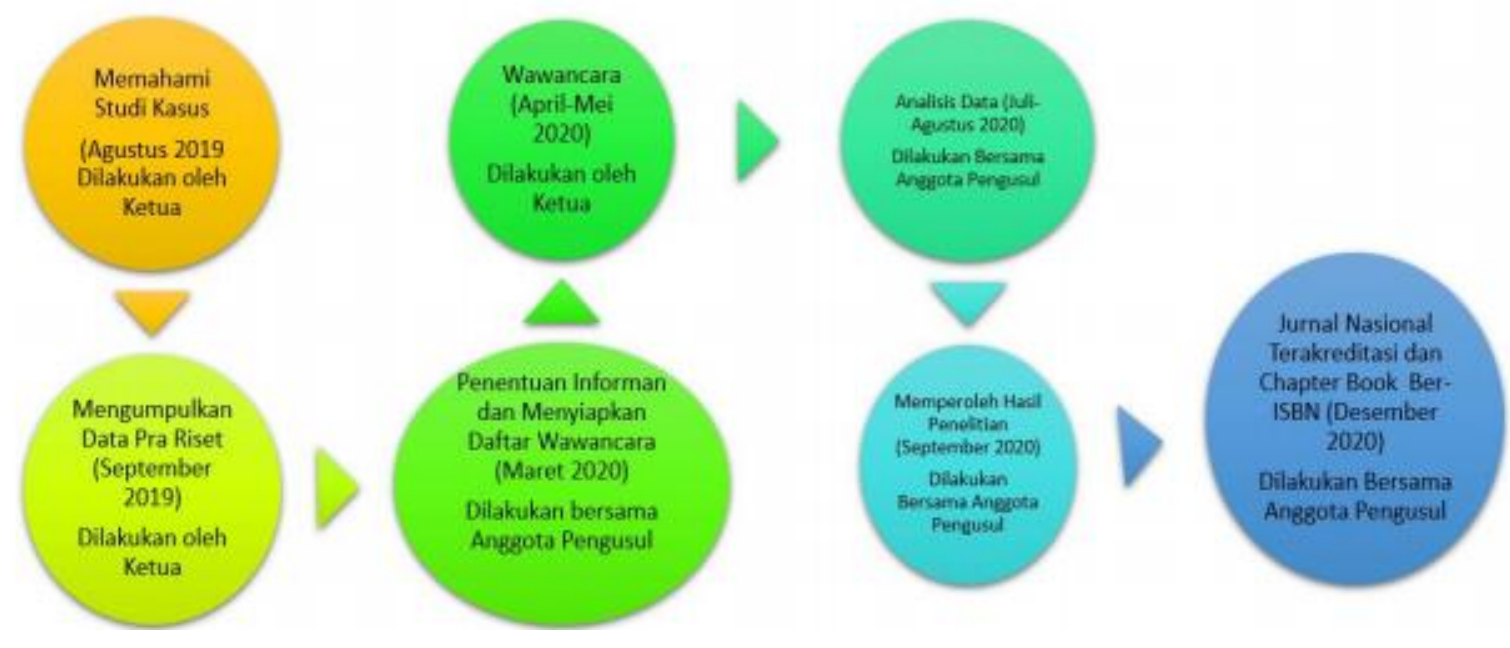

Gambar 2. Alir Proses Penelitian 


\section{HASIL DAN PEMBAHASAN}

Berbagai rujukan peneliti jadikan acuan untuk melihat dimana posisi penelitian ini. Peneliti mengidentifikasi penelitian-penelitian terdahulu untuk melihat pembaharuan serta state of the art dalam penelitian ini. Teori pilihan rasional pada umumnya berkaitan dengan studi kepemiluan yang untuk menunjukkan bagaimana perilaku politik para pemilih dalam menentukan pilihan politiknya. Dalam kajian political behavior, ada tiga pendekatan yang menjadi basis dalam membaca mengenai perilaku memilih yakni The Columbia Study, The Michigan Model dan Rational Choice. Ketiga pendekatan tersebut kemudian lebih sering dikenal dengan istilah sosiologis, psikologis dan pilihan rasional. Selain pendekatan tersebut, ada juga pendekatan lain yang dikembangkan oleh Lau dan Redlawsk. Lau dan Redlawsk mengatakan bahwa pendekatan perilaku memilih ada rational choice, early socialization, fast and frugal dan bounded rationality. Pendekatan pilihan rasional adalah pendekatan yang berangkkat dari teori ekonomi (Mujani et, al, 2012). Walaupun teori pilihan rational juga turut mendapatkan bantahanbantahan (Hindess, 2014), namun teori ini tetap reliable untuk digunakan untuk menjelaskan berbagai fenomena politik.

Pilihan Rasional sebenarnya tidak hanya berkutat pada studi politik yang berkaitan dengan pemilu, melainkan sebuah penjelasan dimana demokrasi bias dikaji dalam perspektif ilmu ekonomi (Roth, 2008). Elster (2008) berpendapat bahwa manusia ketika dihadapkan pada beberapa jenis tindakan, ia akan memilih sesuatu berdasarkan manfaat yang terbaik yang akan di dapatkannya. Pada prakteknya, teori pilihan rasional sering di implementasikan untuk menganalisis perilaku pemilih dalam pemilu. Pilihan rasional sering dianggap sebagai salah satu teori yang dapat menjelaskan fenomena politik uang yang beredar di masyarakat. Namun dalam penelitian kali ini, teori pilihan rasional digunakan sebagai bingkai untuk mengetahui alas an rasional yang melatar belakangi caleg muda yang berkompetisi memperebutkan kursi DPRD Kota Pekanbaru di tahun 2019. Orientasi caleg muda yang sesungguhnya sehingga mau mencalon kan diri sebagai anggota DPRD Kota Pekanbaru akan terungkap seiring dengan dipilih nya teori pilihan rasional sebagai teori utama dalam penelitian ini. Teori elit kemudian juga digunakan dalam penelitian ini sebagai teori pendukung.

Dalam kajian politik, elit adalah sekelompok orang yang berkuasa dalam sebuah struktur sosial, baik secara formal maupun informal. Pengertian tersebut merujuk pada istilah yang dikemukakan oleh Putnam dkk (Mas'oed dan Andrews, 2011). Laswell (2017) mengatakan bahwa elit politik mencakup semua pemegang kekuasaan dalam suatu struktur politik. Elit ini adalah hasil dari metamorfosa orangorang yang berhasil menduduki suatu tempat dalam system politik dan kehidupan masyarakat. Mills (1996) berpendapat bahwa elit-eleit tersebut dapat mengambil keputusan-keputusan yang memberikan dampak luas bagi masyarakat. Dalam teori elit, dijelaskan elit ada dua bagian, yaitu elit politik lokal dan elit non politik lokal.

Elit politik local adalah orang yang menduduki jabatan politik pada ranah eksekutif maupun legislatif. Mereka dipilih melaui pemilihan umum di tingkat lokal. Dalam kaitannya dengan peran di ranah pemerintahan, mereka adalah orang yang membuat serta menjalankan berbagai kebijakan maupun keputusan politik. Posisi para elit ini berada pada jabatan seperti Gubernur, Bupati, Walikota, Anggota DPRD dan pimpinan partai politik. Elit non politik local dimaksudkan pada sebuah posisi yang memiliki kedudukan strategis dan memiliki pengaruh yang kuat untuk memerintah orang lain di tengah-tengah masyarakat. Elite Keagaaman, elit organisasi kemasyarakatan adalah contoh teat untuk menjelaskan posisi bagi elit non politiklokal. (Varma, 1987). Anggota DPRD merupakan salah satu posisi yang bias merepresentasikan konsep elitsecara formal. Anggota DPRD adalah Elit politik lokal. Dalam posisi ini, caleg muda adalah segelintir orang yang akan bermetamorfosis menjadi elit Transformasi manusia biasa menjadi elite ini adalah bentuk untukmenaikkan strata sosial di dalam kehidupan bermasyarakat. 


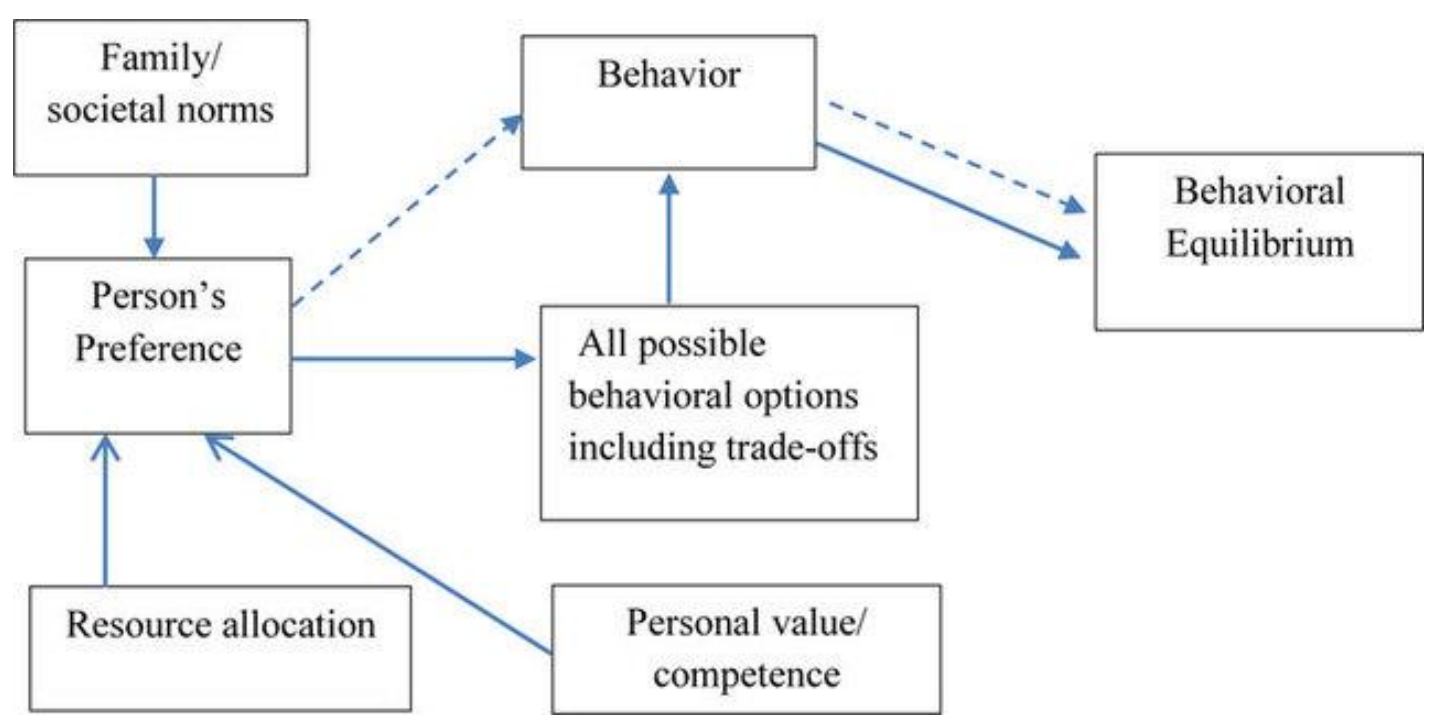

Gambar 2. Kerangka Teori Pilihan Rasional (Friedman \& Hechter, 1988)

Keberadaan legislatif pada ranah pemerintrahan daerah memiliki fungsi untuk terwujudnya pengasawan terhadap penyelenggara pemerintahan daerah ditingkat lokal, sehingga proses check and balances juga terlaksana pada tataran pemerintah lokal. Dewan Perwakilan Rakyat Daerah Kabupaten/ Kota juga merupakan sarana legal bagi masyarakat sipil untuk dapat terjun secara real dalam perumusan kebijakan - kebijakan strategis di daerahnya. Oleh karena posisi anggota DPRD merupakan wujud dari pergerseran posisi masyarakat biasa menjadi elit dalam tataran kekuasaan di Daerah. Posisi elit daerah menjadi hal yang menaraik untuk diperbutkan masyarakat daerah dengan berbagai tujuan dan kepentingan. Pada pemilihan umum anggota DPRD Kabupaten Kota se Indonesia pada tahun 2019 yang lalu terdapat fenomena menarik dimana banyak nya kaum muda yang ikutan dildalam kancah perpolitikan daerah maupun nasional, hal ini barangtentu menimbulkan pertanyaan yang mendasar yakni apa motif serta alasan dari kaum muda ini memilih karir dalam dunia perpolitikan daerah.

Kota Pekanbaru merupakan salah satu Kota dengan jumlah caleg yang cukup banyak di Indonesia, seperti terlihat pada gambar berikut :

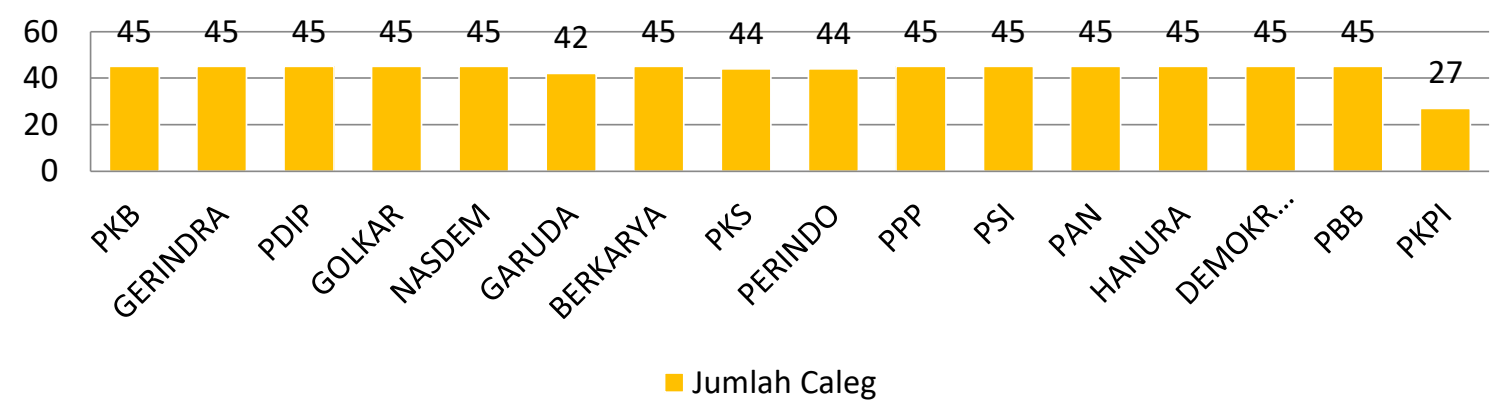

\footnotetext{
Gambar 3. Jumlah Calon Anggota Legislatif DPRD Kota Pekanbaru Berdasarkan Jenis Partai pada Pemilu 2019
} 
Dari gambar diatas tercatat pada KPU Kota Pekanbaru ada sebanyak 697 orang Calon Anggota Legislatif yang bertarung pada Pemilihan Umum Anggota DPRD Kota Pekanbaru tahun 2019. Semua calon anggota legislative tersebut tersebar kedalam 16 partai politik perserta pemilu 2019. Bila melihat sebaran caleg DPRD Kota Pekanbaru berdasarkan daerah pemilihan (dapil) dapat dilihat pada gambar berikut :

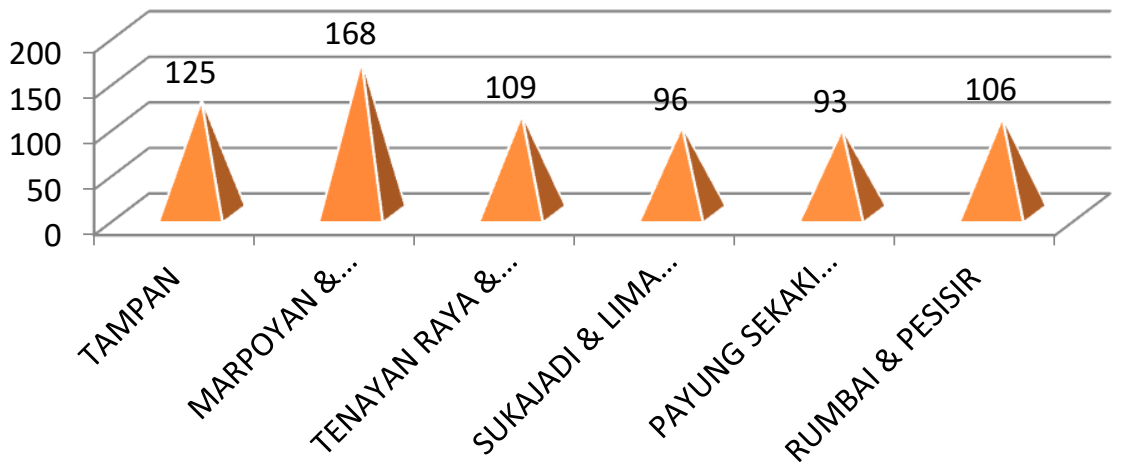

- Jumlah Caleg

\section{Gambar 4. Jumlah Calon Anggota Legislatif DPRD Kota Pekanbaru Berdasarkan Daerah Pemilihan (Dapil) pada Pemilu 2019}

Sebaran caleg pada daerah pemilihan di Kota Pekanbaru memliki rata - rata 116 orang per dapilnya, ini menunjukan animo masyarakat yang mencoba untuk masuk kedalam ranah elit daerah melalui DPRD Kota Pekanbaru cukup tinggi. Total calegsebanyak 697 orang tersebut akan memperebutkan 45 kursi anggota legislatif pada DPRD kota Pekanbaru. Adapun hasil pemilihan umum DPRD Kota Pekanbaru tahun 2019 dapat dilihat pada gambar berikut :
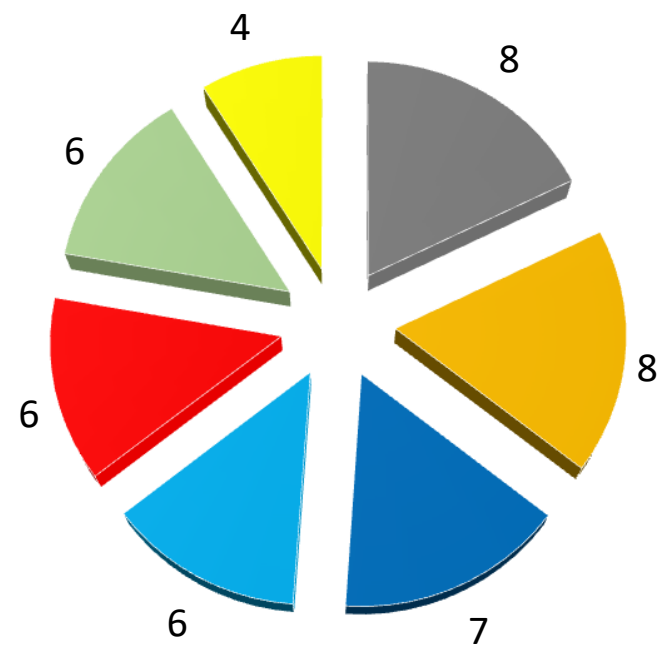

$$
\begin{aligned}
& \square \text { PKS } \\
& \text { GERINDRA } \\
& \square \text { DEMOKRAT } \\
& \square \text { PAN } \\
& \square \text { PDIP } \\
& \square \text { HANURA/NASDEM } \\
& \text { GOLKAR }
\end{aligned}
$$

\section{Gambar 5. Jumlah Anggota Legislatif DPRD Kota Pekanbaru Terpilih Berdasarkan Jenis Partai pada Pemilu 2019}

Dari hasil pemilihan umum DPRD Kota Pekanbaru tahun 2019 Partai Gerinda dan PKS menjadi pemenang dengan jumlah kursi terbanyak yakni 8 kursi, diikuti Demokrat 7 kursi kemudian PAN, PDIP 
dan gabungan komisi partai Hanura dan Nasdem masing -masing 6 Kursi serta terakhir Golkar dengan 4 Kursi. Terdapat dua anggota legislative muda yang mengisi dinamika perpolitikan DPRD Kota Pekanbaru. Mereka adalah Ginda Burnama,ST yang berumur 28 tahun dari partai Gerindra, dan Sovia Septiana, S.Sos yang berumur 30 tahun dari partai Golkar. Mereka tercatat sebagai anggota termuda dalam susunan anggota DPRD Kota Pekanbaru periode 2019 - 2024.

Untuk mebedah alasan para caleg muda yang memilih untuk terjun kedunia politik, peneliti menggunakan Teori Pilihan Rasional (Friedman \& Hechter, 1988) teori ini digunakan untuk menelisikalasan rasional dari para caleg muda dalam kontestasi politik pada tahun 2019 di Kota Pekanbaru.

\section{Sumber Pendanaan Kampanye Caleg Muda di DPRD Kota Pekanbaru}

Sumber pendanaan kampanye menjadi salah satu aspek terpenting pada saat seorang calon baik yang maju dalam ranah eksekutif maupun legislatif untuk berkompetisi dalam sebuah pemilihan langsung oleh rakyat. Dalam era politik modern, kebutuhan akan dana politik untuk membiayai kamapanye politik, memainkan peranan utama dalam kontestasi politik. Hampir semua peserta pemilu masih beranggapan, jikakemenangan dalam suatu kontes electoral ditentukan dengan seberapa massif kampanye politik dilakukan (Saputra, 2004). Pendanaan kampanye berkaitan dengan dari mana sumber dana kampanye, pembatasansumbangan, dan larangan sumbangan yang diperoleh oleh masing-masing calon anggota legislatif yang mengikuti pemilu.

Pengaturan penerimaan dana kampanye bertujuan untuk memastikan bahwa dana kampanye yang digunakan oleh partai politik peserta pemilu maupun calon anggota legislatif, benar-benar dana yang sahmenurut undang-undang. Hal ini dimaksudkan karena penggunaan dana kampanye yang didapat dengan cara tidak sah adalah sebuah pelanggaran dan menimbulkan ketidak setaraan bagi calon peserta pemilu (Anjalline, R.A. Anggraini, \&Indrayati, 2014).

Kampanye pileg kali ini telah menghadirkan fenomena kontes individu ketimbang kontes partai. Hal ini tecermin dari semakin besarnya peran caleg sebagai aktor dan kekuatan individu dalam mewarnai pelaksanaan kampanye Transformasi perana ktor ini sesungguhnya dapat dilihat juga sebagai sebuah transformasi peran partai (Brown, 2009). Sistem proporsional dengan suara terbuka yang diterapkan saat ini pada akhirnya akan menimbulkan dampak terjadinya pasar bebas dalam pemilu. Pengalaman Pemilu 2009 yang lalumemperlihatkan bagaimana setiap kandidat pemilu legislative saling bersaing dan menghabiskan dana yang fantastis untuk kampanye. Untuk menjamin fairness dan equality dalam pemilu, maka diperlukan sejumlah aturan main. Salah satu gagasan yang telah diterapkan oleh sejumlah negara adalah dengan pemberlakuanpembatasan dana kampanye (limitation/campaign cap) (Junaidi, 2012).

Dalam konteks pemilihan di DPRD Kota Pekanbaru, sumber pendanaan kampanye ini menjadi salah satu hal yang difokuskan untuk diteliti. Caleg muda (di bawah 30 tahun) sudah banyak yang turut andil dalam politik secara praktis, terlebih untuk Kota Pekanbaru. Untuk menghindari angka golput yang lebih banyak, nampaknya beberapa partai politik mulai memperhitungkan Caleg (Calon Anggota Legislatif) mudasebagai salah satu pion yang mereka kerahkan untuk dapat menarik perhatian masyarakat. Walaupun saat ini anak-anak muda masih dianggap belum cukup kritis menanggapi berbagai masalah politik, namun mayoritas masyarakat masih optimis dengan adanya tokoh muda yang akan mampu memimpin bangsa lebih baikdari pada tokoh-tokoh lama yang saat ini telah banyak mendominasi perpolitikan nasional (Permata sari, 2014). Mungkin saja kegalauan masyarakat ini dipicu oleh kurang berhasilnya reformasi dalam melakukan regenerasi kepemimpinan politik di Indonesia ini. Pada kenyataannya, walaupun telah dilangsungkannyapemilu-pemilu pada periode-periode sebelumnya, ternyata tidak terlalu banyak pemimpin dari kelompokmuda yang berhasil menerobos kedalam struktur politik yang telah dikuasai tokoh-tokoh yang lebih mapan (Permata sari, 2014). 
Mengenai sumber pendanaan kampanye, juga bias dihubungkan dengan konsep modal yang diutarakan oleh Pierre Bourdieu. Konsep modal yang dapat membingkai konsep sumber pendanaan kampanye adalah modal ekonomi. Menurut Bourdieu, modal ekonomi, yang di antaranya adalah alat-alat produksi (mesin, tanah, tenaga kerja), materi (pendapatan, benda-benda), dan uang. Modal ekonomi merupakan modal yang secara langsung bias ditukar, dipatenkan sebagai hak milik individu. Modal ekonomi merupakan jenis modal yang relatif paling independen dan dan fleksibel karena modal ekonomi secara mudah bias digunakan atau ditransformasi kedalam ranah-ranah lain (Krisdinanto, 2016). Dalam konteks kampanye, modal ekonomi adalah kemampuan finansial yang dimiliki caleg untuk berkompetisi dalam pemilu. Caleg muda dianalogikan sebagai orang yang baru memulai untuk sebuah perjalanan kemapanan, dalam artian lain, dianggap secara naluriah belum dapat mapan secara ekonomi karena masih proses. Namun tentunya hal ini dikecualikan ketika caleg muda tersebut berasal dari keluarga yang mampu, yang kemudian dapat menopangsumber pendanaan kampanye.

CA, seorang anak muda yang pada saat berkontestasi pada pemilu masih berumur 24 tahun. CA adalah salah caleg muda yang bertarung di pileg 2019 untuk daerah Kota pekanbaru dari daerah pemilihan Pekanbaru 1 (Sukajadi, Pekanbaru Kota dan Lima Puluh). CA maju melalui partai Gerindra. Di usianya yang masih relative muda, CA baru saja menyelesaikan Studi S2 nya disalah Satu Universitas di Kota Pekanbaru. CA adalah salah satu caleg muda yang gagal duduk di Kursi DPRD Kota Pekanbaru karena kalah dari caleg incumbent di daerah pemilihannya. Menurut penuturannya, CA menghabiskan biaya kampanye sebesar kurang lebih 450 Juta Rupiah.

"Aku ngeluarin uang untuk kampanye ya sekitaran 450 Jutalah. Itu berasal dari orang tuaku dan juga keluarga-keluarga lain tentunya. Aku punya tim pemenang berkisar 80 orang dan tim pemenang anaku di komandoi oleh om aku sendiri”

Dana kampanye yang cukup besar tersebut diakuinya adalah termasuk yang biasa aja disbanding dengan caleg lainnya. Namun CA mengatakan bahwa harus ada yang dikorbankan, salah satunya adalah dana. CA adalah salah satu caleg yang bias dikatakan sebagai orang yang berada di level menengah keatas. Ia mengakui bahwa kemungkinan besar akan kembali bertarung untuk Kursi DPRD Kota Pekanbaru pada tahun 2024 nanti.

"Jujur, keinginan untuk kembali maju di pileg 2024 masih ada. Pileg 2019 bisa jadi bahan evaluasi aku sendiri tentunya agar bisa optimal nantinya"

Berbeda dengan $\mathrm{R}$, seorang caleg yang juga masih muda. $\mathrm{R}$ maju dengan modal yang tidak terlalubesar yakni masih di bawah 100 Juta Rupiah. R mengatakan bahwa ia mengikuti kontestasi pemilihan umum dengan modal yang terbatas, dan itu merupakan hasil tabungan yang ia kupul kan di tambah dengansumbangan dari keluarga. $R$ dengan dana yang kecil tersebut pun gagal masuk di DPRD Kota Pekanbaru.

"Saya hanya menghabiskan dana yang kecil. Jauhlah di bawah caleg- lain yang bias ratusan bahkan miliaran rupiah. Saya hanya habis dikisaran dibawah 100 Juta. Yah saya cukup kecewa dengan hasil ini, namun yang penting saya sudah berusaha"

Hal yang serupa juga diungkapkan oleh Z, Pemuda 27 Tahun yang juga bertarung merebut kursi. $\mathrm{Z}$ mengatakan bahwa ia mendapatkan sumber dana dari sumbangan keluarga dan tabungan pribadinya. Dana yang $\mathrm{Z}$ habiskan hanya sekitar 80 Juta rupiah yang habis untuk operasional kampanye dan juga untuk memasang berbagai alat peraga layaknya poster, baliho, spanduk dll. 
"Saya habis 80 Juta Rupiah. Itu adalah hasil tabungan saya dan juga sumbangan keluarga saya terutama papa saya. Ini adalah langkah awal. Dan saya insyaAllah bakal bertarung lagi di pemilu 2024"

RS, adalah pemudi berusia 25 tahun yang mencoba peruntungannya pada pemilu 2019. RS mengikuti Pemilu karena dorongan keluarga terutama ayahnya yang juga seorang tokoh di daerah tempat tinggalnya. RS menghabiskan dana kampanye sebera 200 Juta Rupiah yang juga berasal dari sumbangan orang tuanya dan sedikit tabungan yang dimilikinya.

"Saya habis kurang lebih 200 Juta. Hampir semua sih adalah uang papa dan ada juga sedikit uang tabungan saya. Saya maju juga karena dorongan orang tua. Dan juga saya pengen mengabdi untuk negara melalui Jalur Legislatif daerah ini”

FHR seorang pemuda yang juga menjadi caleg dari partai yang baru mulai berpartisipasi di Pemilu 2019. FHR menceritakan bahwa ia hanya coba-coba saja untuk ikut di Pemilu 2019. Awal mulanya, ia langsung ditawari oleh pengurus partai untuk menjadi caleg dan ia pun langsug menanggapi positif tawaran itu. FHR tidak menghabiskan uang lebih dari dua juta rupiah untuk ikut berkampanye.

"setelah ditawari oleh partai, saya langsung mau. Dan saya ingin saja berpartisipasi langsung dalampemilu. Istilahnya coba-coba. Saya pun hanya menghabiskan dana sebesar tak sampai 2 juta rupiah. Jumlah yang sangat sedikit tentunya"

Penggunaan dana kampanye juga menjadi hal yang turut peneliti tanyakan kepada informan CA, salah seorang caleg yang diwawancarai mengatakan bahwa ia tidak memberikan uang kepada calon pemilih, melainkan uang yang dihabiskann lebih kepada untuk mobilisasi tim inti dan juga untuk pembuatan alat peraga kampanye seperti baliho, spanduk dll. CA juga mengatakan juga member bantuan untuk para konstituennya dengan bentuk hal-hal yang digunakan secara kelompok dan bermanfaat bagi sesame. Namun CA enggan untuk menyebutkan apa saja bantuan yang diberikan kepada calon konstituennya.

"saya tidak mau memberikan amplop atau yang lebih sering disebut sebagai serangan fajar atau politik uang. Namun, saya juga turut memberikan hal-hal yang bermanfaat bagi kelompok masyarakat yang bias digunakan Bersama. Tentunya saja juga menghabiskan uang yang cukup besar untuk penyediaan alat peraga dan juga mobilisasi operasional tim yang membjantu saya untuk kampanye.

Hal yang sama juga dilakukan oleh $\mathrm{R}$, seorang caleg muda yang menghabiskan dana kampanye tidak lebih dari 100 Juta Rupiah. R mengakatan, dana kampanye dia hanya banyak

Dihabiskan untuk membuat alat peraga kampanye seperti baliho, spanduk, dan kartu nama serta poster. Kemudian selebihnya, $\mathrm{R}$ menggunakan dana kampanye pribadinya untuk mengadakan pertemuan denganwarga sekitar yang masuk di area dapilnya.

"saya paling untuk penggunaan dana kampanye hanya untuk seputar membuat baliho, poster, kartunama dan spanduk. Kemudian sisanya saya gunakan untuk operasional bertemu dengan warga-warga disekitar dapil saya. Itu saja" 
Dari beberpa hasil wawancara yang peneliti lakukan diatas, dapat dilihat bahwa rata-rata para caelg muda Kota Pekanbaru memiliki sumber daya yang cukup kuat dalam basis finansial, sehingga mereka dapat mengalokasikan banyak biaya pada alat peraga kampanyenya. Modal financial tidak hanya basis bagi para caleg muda dalam bertarung dalam konstestasi politik pemilu DPRD Kota Pekanbaru ini. Banyak kalangan pemuda ini juga memiliki basis keukutan keluarga yang menjadi salah satu factor kuat untuk dapat memenagkan kontestasi politik.

\section{KESIMPULAN}

Dari beberpa hasil wawancara yang peneliti lakukan diatas, dapat dilihat bahwa rata-rata para caelg muda Kota Pekanbaru memiliki sumber daya yang cukup kuat dalam basis finansial, sehingga mereka dapat mengalokasikan banyak biaya pada alat peraga kampanyenya. Modal financial tidak hanya basis bagi para caleg muda dalam bertarung dalam konstestasi politik pemilu DPRD Kota Pekanbaru ini. Banyak kalanganpemuda ini juga memiliki basis keukutan keluarga yang menjadi salah satu factor kuat untuk dapat memenagkan kontestasi politik

Keluarga bukan saja menjadi penopang utama dalam modal ekonomi seorang caleg untuk dapat berpartisipasi dalam pemilu, melainkan juga menjadi pendorong motivasi caleg muda untuk mau menjadi caleg. Rata-rata, caleg muda banyak yang berasal dari keluarga berpengaruh yang berlatar belakang seperti politisi, pengusaha kaya, maupun ASN/mantan ASN yang mempunyai jabatan tinggi. Caleg muda kemudian mengambil posisi untuk turut berpengaruh dalam arena kekuasaan ditingkat lokal.

\section{SARAN}

Dalam proses pemilihan umum sebaiknya lebih memberikan peluang serta informasi yang baik bagi para pemuda untuk dapat terlibat sebagai calon anggota legislatif. Bagi para calon anggota legislatif yang berusia muda diharapkan tidak hanya memilki basis keuangan dan financial saja, akan tetapi juga basis kemampuan serta kapabilitas dalam praktek political will yang baik di masyarakat.

\section{DAFTAR PUSTAKA}

[1] Mujani,S.,Liddle,R.W.,\&Ambardi,K. (2012). Kuasa rakyat:Analisis tentang perilaku memilih dalampemilihanlegislatif dan presiden Indonesia pascaordebaru. Mizan Media Utama.

[2] Hindess, B. (2014). Choice, Rationality and Social Theory (RLE Social Theory). Routledge.

[3] Roth, D. (2008). StudiPemiluEmpiris: Sumber, Teori-teori, Instrumen dan Metode. Jakarta: Für Die Freiheit.

[4] Elster, J. (2009). Interpretation and rational choice. Rationality and Society, 21(1), 5-33.

[5] Mochtar, M. O., \& Mac Andrew, C. (2008). PerbandinganSistemPolitik. Gadjah Mada University Press

[6] Lasswell, H. D. (2017). Power and personality. Routledge. 
[7] Woodard, C. (1956). THE POWER ELITE, by C. Wright Mills, Oxford University Press, New York, 1956. Pp. 423. Louisiana Law Review, 17(1), 35.

[8] Varma, P. S. (1987). TeoriPolitik Modern, terjemahan. Jakarta. CV. Rajawali.

[9] Yin, R. K. (2006). Case study methods. Handbook of complementary methods in education research, 3, 111-122.

[10] Tongco, M. D. C. (2007). Purposive sampling as a tool for informant selection. Ethnobotany Research and applications, 5, 147-158.

[11] Friedman, Debra., dan Hechter, Michael. 1998. The Contribution of Rational Choice Theory to Macrosociological Research. Sociological Theory. 